\title{
Long-term Mechanism on The Decreasing Rate of Passing The Postgraduate Entrance Examination in Some Higher Engineering Colleges and Universities
}

\author{
Shuwang Chang ${ }^{1, a}$, Yan Jing ${ }^{2, b}$ and Zhun $\mathrm{Ye}^{3, \mathrm{c}}$ \\ ${ }^{1,3}$ School of Mechanical, Electronic and Information Engineering, Shandong University, Weihai, \\ 264209, Shandong, China \\ ${ }^{2}$ Corresponding author, School of Information and Electrical Engineering, Harbin Institute of \\ Technology, Weihai, 264209, Shandong, China \\ àshwchang@sdu.edu.cn, bjingyan@hitwh.edu.cn, c'zhunye@sdu.edu.cn
}

\begin{abstract}
Keywords: Passing rate of the postgraduate entrance examination, Long-term mechanism, Management of teaching resources, Scientific and effective guidance
\end{abstract}

\begin{abstract}
The passing rate of the postgraduate entrance examination (PRPEE) is one of the indicators for evaluating the quality of running a school, college or university. It is a systemic issue and involves a wide range of factors. The in-depth survey about the declining PRPEE in some higher engineering colleges and universities is done in this paper, and the guiding principles are given for establishing a long-term response mechanism. A series of feasible suggestions are given from three aspects including colleges and universities, schools and departments, and the students, which includes scientific management of the self-study rooms, improving the supplemental exam strategy for the students, promoting harmonious interaction between teaching and learning, developing a systematic plan of lectures and experience exchanges about the postgraduate entrance examination (PEE), establishing and improving the scientific and effective guidance mechanism covering the whole process of attending the PEE, and improving students' abilities to cope with PEE. All of these will make a positive effect on the rising of PRPEE.
\end{abstract}

\section{Introduction}

The quality of personnel training is the core of the issue on passing the postgraduate entrance examination (PEE), which is determined by the guiding ideology of running the college/university, resources, and the level and ability of running a college/university. Although the orientation of the higher engineering colleges and universities are different, most of them have expectations for the passing rate of postgraduate entrance examination (PRPEE). In recent years, the PRPEE decreases in some higher colleges and universities, which even bring certain impact on the normal running of some colleges and universities. The reason of the decreasing includes national postgraduate training policy [1], social environment, development strategies of the colleges and universities, employment of the graduate students, and the understanding of attending PEE [2][3]. Based on in-depth survey, the long-term countermeasure and mechanism to solve the decreasing rate of passing the PEE is studied systematically in this paper.

\section{Guiding Principles}

The PRPEE is a metric of evaluating the quality of running higher colleges and universities. The higher engineering colleges and universities should take Double First-rate construction as an opportunity, increase the degree of attention and strengthen the unified leadership based on their own orientation of running the college/university. Although the colleges and universities should not emphasis and aspire and bring the butterfly effect [4], they should handle it correctly. The countermeasure and mechanism should not affect the normal teaching and research activities, meanwhile, better relevant guidance and service work should be provided. Both of the improvement 
of the teaching quality, and the cultivation of study style construction [5] should be emphasized. On the basis of the previous work, all teaching units should strengthen and perfect the corresponding working mechanism and methodologies, strengthen the guidance and instructions for students who will attend the PEE, and thus improve the passing rate of the PEE.

\section{The aspect of colleges and universities}

As the first level teaching unit, colleges and universities are responsible for the institution's orientation, development and planning, policies and regulations, and allocation and scheduling of all kinds of resources, which will affect students' attending of the PEE.

(1) Creating a good learning atmosphere

First of all, engineering colleges and universities should pay attention to the quality of undergraduate training according to the institution's historical period and current level of running the school. In particular, the college and university should pay more attention to the matching issue between teaching resources, teaching conditions and environment, and personnel training objectives. The starting point and the work should be carried out around the students' growth and development.

Although, study is not the whole part of college life, a higher college or university should have a good learning atmosphere. In recent years, there are some negative changes in the overall learning environment in some colleges and universities due to a variety of factors. The teaching and learning atmosphere and discipline should be systematic managed from top to bottom. It is not enough if only a small part of the teachers and students are conscious of the management, even the little effect are not up to.

(2) Scientific management of the self-study rooms

Self-study room resources are usually managed by the colleges and universities, the number of which are gradually being limited with the college enrollment expansions. The college or university should investigate the number of students who has registered for the PEE and reasonably open self-study rooms for these students. The management of the self-study rooms should be strengthened, which includes the regulations of using these special purpose classrooms and the punishment for buying and selling seats, the aim is to ensure that these students will have a fixed study space and a good learning atmosphere.

(3) Better accommodation and catering

Learning, eating and sleeping are the three major issues in the half year before the exam for most of the students who are going to attend the PEE. It is important for the students to have good diet and enough sleep. Colleges and universities should open a reasonable number of student dining halls and student accommodations for these students during the summer holiday. The college should not deal with the students' accommodation and catering issues only from the management point of view.

(4) Improving the supplemental exam strategy for the students

The PEE and the semester's final exam is usually very close in time. It is difficult for the exhausted students who are preparing the entrance exam to pass the course exam. Even if they can separate some time for the course, the learning quality of the corresponding course is also very worrying. So that, colleges and universities should consider opening green light for some of the students who are going to attend PEE, by allowing them to take the supplemental exams of the courses if they applied to do so, in order to give them enough time for preparing the entrance exam.

(5) Controlling the number of extracurricular activities

Students who are going to attend the PEE are looking forward to have more dedicated time and peace of mind for preparing the exam, and do not want to be bothered because of some extracurricular activities. The corresponding departments of colleges and universities should control the number of activities for them to a reasonable level and reduce the activities with little significance. 


\section{The aspect of schools and departments}

As the secondary teaching units, schools and departments are responsible for carrying out the policies from colleges and universities, managing teaching and research activities, and students work and so on. They directly affect the students who are going to attend the PEE.

(1) Giving due attention and strengthen unified leadership

Schools and departments should give due attention to the students and strengthen unified leadership because the PRPEE will be finally generated from the school. A leading group should be created which including leader of the school or department, counselors and some professional course teachers. It is responsible for the coordinated work of various departments and the mobilization, letting students understand the corresponding policies and regulations and definitely know the purpose and significance of attending the PEE and calmly face it. The schools and departments should encourage students to attend the PEE and provide the necessary support to students who plan to do that.

(2) Promoting harmonious interaction between teaching and learning, and creating a good academic atmosphere

Teaching and learning should be complementary and mutually reinforced, however, in recent years, there are some problems in the linkage of these aspects. Although many schools and departments have taken some measures and there are some good changes, the real benign interaction effect has not been achieved. Schools and departments should consider taking further measures to create a good teaching and learning atmosphere, such as, (a) taking further measures to promote mutual communication among teachers, counselors and students, and eliminating the problem in the bud state; (b) grasping the scale based on students as the main body, not only understanding and even tolerating students' nature, but also firmly grasping the bottom line without blind concession; (c) encouraging professional course lecturers to carry out the mobilization in order to encourage the students to attend the PEE; (d) strengthening students' management and assessment, not only focusing on the results assessment, but strengthening process management in rigorous and strict principles.

(3) Establishing and improving the summer camp guidance mechanism

In recent years, many colleges and universities carry out a series of academic summer camps, which becomes camps of postgraduate recommendation. It is certainly helpful to attend the summer camp for students wishing to be postgraduates because they can meet supervisors and corresponding staff in advance. However, many students are often distressed for selecting one or more suitable summer camps. The reason is not only many summer camps are conflict in time, but also the number of summer camps is not the more the better. Schools and departments should provide appropriate guidance for the students and let them have clear objectives and attend high quality summer camps.

(4) Developing a systematic plan of lectures and experience exchanges about the PEE

Many students prefer to attend good and inspiring lectures about the PEE and learn experience and lessons from their seniors. Therefore, schools and departments should meet students' demand as much as possible. The school should investigate and then develop a systematic plan of lectures and experience exchanges meetings about the PEE. By learning the experience from some experts, teachers and successful students, the students will take shortcuts and make their directions clearly, thus the possibility of success should be increased.

(5) Establishing and improving the scientific and effective guidance mechanism covering the whole process of attending the PEE

The PEE is just like another college entrance examination, but it is different from last college entrance examination. It is necessary to provide essential psychological counselling for students attending the PEE, and proper guidance can help students rise to the examination with better status.

In our investigation, it is found that there are many problems for the students who are going to attend the PEE, such as blind application, unreasonable reviewing plans, and poor performance in 
the first examination or re-examination and so on. For resolving these problems, schools and departments should consider to establish and improve a set of guidance mechanism covering the whole process including applying, preparing, attending first examination and attending re-examination. Students who obtained these scientific and effective guidance can meet the examination challenges with better gestures and full of enthusiasm and confidence.

(6) Establishing and improving the review guidance and Q\&A mechanism of professional courses

Some professional courses will be included in the first examination and re-examination in the PEE. Most of the students usually spend only 2-3 months for reviewing these courses. Many students often encounter difficulties in the review process because of the limited time, and they are lacking of training courses for these professional courses, which will directly affect students' examination results. Thus, schools and departments should take some measures to establish and improve a set of review guidance and Q\&A mechanism of professional courses by encouraging some excellent professional courses teachers to participate. The mechanism is necessary for students' review process.

(7) Building an internal information and resource sharing platform

It isn't necessary for every single student who is going to attend the PEE to search information and material repetitively, which because not only everyone's energy is limited, but also some information and material are public. Building an internal sharing platform about information and material of the PEE can not only help students save time, but also provide space for studying and discussion, which will play a positive role of raising students' PRPEE.

(8) Strengthening alumni contact mechanism and servicing for students attending the PEE

Alumni, especially those who attended the PEE is an important resource for many students who are going to attend the PEE. The students hope to get guidance and help from seniors. However, many alumni' contact information changed because of their finishing the school. If the contact information mechanism is built and strengthened by the school or department, which not only will facilitate the students, but also is very favorable for school or department's long-term development.

(9) Organizing and guiding students to carry out teamwork and creating a strong learning atmosphere

Attending the PEE is a private issue, but it should not be a personal battle. Mutual encouragement and mutual inspiration among classmates are very useful. However, some students are ashamed to cooperate with others. If schools and departments can take some measures to promote students to establish teams or learning groups or other organizations to cooperate with others, it will guide students to develop healthily, prepare the PEE earnestly and will be helpful for raising the PRPEE.

(10) Improving the quality of student's second classroom activities and reducing the number of unnecessary activities

Schools and departments should carry out necessary research and feasibility studies about the number and quality of students' second classroom activities, make scientific and reasonable plans, and provide group and individual guidance, in order to reduce the impact on students attending the PEE, because they already have spent some time on the activities of colleges and universities.

\section{Aspect of students}

(1) Setting clear goals and developing detailed plans

There are three main directions for the student after they graduate, namely the employment, being graduate students and study abroad. Students should take into consideration about many factors and make their choice before the junior year as much as possible. If the goal is to attend the PEE, students should make the review plans in detail and try to carry out it as the schedule.

(2) Collecting information from different sources, carefully selecting schools and majors and carrying out targeted review

Students should collect information from different sources before attending the PEE and make a 
choice after having in-depth and comprehensive understanding about the target schools and majors. Then students should carry out targeted review according to the exam's outlines and do not fight without prepared battle.

(3) Mentality Adjusting, maintaining perseverance strengthening self-discipline

Attending the PEE is a long, boring and tough thing, students will encounter a lot of problems and difficulties in halfway. Students need to have better mentality, can actively face difficulties and seek methods to solve them, and can adhere to the end. At the same time, students should strengthen self-discipline and resist the relevant temptation, be able to go back to the normal track as soon as possible when they are in emotional trough.

(4) Learning others' lessons and actively carrying out teamwork

Learning other people's lessons can help students avoid detouring, improve efficiency and the review process's quality. It is undeniable that carrying out teamwork can help encouraging each other and make a corporately promotion.

\section{Conclusion}

The passing rate of the postgraduate entrance examination is one of the indicators for evaluating the quality of running a school, college or university. It involves in a wide range of factors, such as external influence factors, the level of colleges and universities, the level of schools and departments, and the students' aspect. Therefore, it is a systemic issue, which can be improved and raised only when we all strengthen coordination and work together.

\section{Acknowledgement}

The research project was funded by the Teaching and Research Fund of the school of mechanical, electronic and information engineering. Thanks for reviewing experts' reviews and suggestions!

\section{References}

[1] Ministry of Education, National Development and Reform Commission, Ministry of Finance. Opinions on Deepening Postgraduate Reform. 2013.03.29

http://old.moe.gov.cn//publicfiles/business/htmlfiles/moe/A22_zcwj/201307/154118.html

[2] Yue Yinhuan, Zhang Jianxin. An Analysis of the Motivations and Influencing Factors of College Students after the Reform of Postgraduate Education. Technology Outlook [J], 2015 (35), 270-272.

[3] Wang Xueying, Zhang Nannan. Study on key factors of graduate entrance examination. Journal of Shenyang Normal University (Natural Science Edition) [J], 2014 Vol.32 No.1 111-119.

[4] Liu Yao. A Butterfly Effect in Universities: From Pursuing the Rate of Attending Exams for Entrance to Graduate Education to Overflow of Exam-oriented Education. Shanghai Journal of Educational Evaluation [J], 2015 (3) 43-47.

[5] Pan Yi, Zhao Jianbo, et al. Research on Reducing Failure and Controlling Dropout in Higher Education. Theory and Practice of Contemporary Education [J], 2016 Vol.8 No.4 108-110.

[6] Wang Li. The Excitation of Postgraduate Entrance Examination for Course Construction of Applied Undergraduate Colleges and Universities. SHANDONG CHEMICAL INDUSTRY [J], 2016 Vol.45, 160-161. 